\title{
Nuclear and mitochondrial genetic structure in two social forms of the fire ant Solenopsis invicta: insights into transitions to an alternate social organization
}

\author{
KENNETH G. ROSS* \& D. DEWAYNE SHOEMAKER $\dagger$ \\ Department of Entomology, University of Georgia, Athens, GA 30602-2603 and +Department of Biology, University \\ of Rochester, Rochester, NY 14627, U.S.A.
}

\begin{abstract}
We describe genetic structure at microgeographical scales in two social forms of the introduced fire ant Solenopsis invicta using nuclear and mitochondrial markers. Fire ant populations in northern Georgia, U.S.A. are structured in fundamentally different ways at the two genomes. Virtually all nuclear genetic variation resides within sampling sites; no differentiation was apparent between the social forms and only minimal differentiation was found among sites in only one social form (the polygyne form, which has nests with numerous queens). In contrast, substantial mtDNA variation exists at all levels; the forms are significantly differentiated and strong divergence was detected among sites in the polygyne form. No mtDNA differentiation was found among sites in the monogyne form (which has nests with a single queen). These results are predicted on the basis of the social biology of the ants. Monogyne queens and males of both forms presumably disperse widely, and polygyne queens commonly mate with monogyne males, thus explaining the uniformity of nuclear allele frequencies across sampling sites and between the forms. Polygyne queens display habits consistent with limited dispersal, and queens of both forms seem unable to establish themselves as reproductives in nests of the alternate form, thus explaining the strong microgeographical structure within the polygyne form and differentiation between the forms found using mtDNA markers. The mtDNA haplotypes are distributed among sites in a manner that suggests a mechanism for the spread of polygyny in introduced fire ants. Monogyne queens apparently mate occasionally with polygyne males and acquire a Mendelian nuclear factor allowing the expression of polygyny in their sexual daughters.
\end{abstract}

Keywords: allozymes, fire ants, genetic structure, mtDNA, social organization, Solenopsis invicta.

\section{Introduction}

Many issues in evolutionary biology revolve around the existence of genetic structure in wild populations (Barton \& Clark, 1990). Thus, evolutionary geneticists seek to document patterns of structure at various scales and to understand how organismal attributes generate these patterns (Avise, 1994). This task is increasingly accomplished by combining knowledge of an organism's natural history with data from diverse molecular markers, including markers with contrasting modes of inheritance that can illuminate the roles of the different sexes and life stages

*Correspondence. E-mail: ross@bscr.uga.edu in mediating gene flow and generating structure (Avise, 1994; Dong \& Wagner, 1994; Hoelzer et al., 1994).

Social organisms are appealing subjects for the study of genetic structure because their social habits can strongly limit gene flow in one or both sexes, leaving a distinctive record of structure detectable with appropriate markers (Chepko-Sade \& Halpin, 1987; Shoemaker \& Ross, 1996; van Staaden et al., 1996). Thus, for instance, more pronounced structure may be detected with mitochondrial DNA (mtDNA) markers than markers of the nuclear genome in social animals with philopatric females and dispersing males (Hoelzer et al., 1994). Moreover, the form of social organization can vary 
substantially within social species (Ross \& Keller, 1995), providing useful comparative contexts for discerning how changes in social behaviour affect genetic structure.

Ants are especially good models for studying the impact of social behaviour on genetic structure for two reasons. First, there is extensive intraspecific variation in social organization, and this variation is often correlated with distinctive reproductive and dispersal behaviours (Bourke \& Franks, 1995; Ross \& Keller, 1995). Thus, knowledge of the social biology of local populations can be used to make predictions about genetic structure. Secondly, the evolution of social behaviour is itself expected to be influenced by local structure, most obviously because such structure reflects patterns of relatedness between interactants (Barton \& Clark, 1990).

The fire ant Solenopsis invicta, an introduced pest in the U.S.A., displays important variation in its social organization. Two distinctive social forms exist in this species, the monogyne (M) form, in which a single egg-laying queen resides in each colony, and the polygyne (P) form, in which numerous such queens reside in each colony. The two forms differ in many features of their social biology expected to affect gene flow patterns within and between them (Ross \& Keller, 1995). For instance, M queens disperse widely during mating flights and found new colonies without workers (independently), relying on extensive nutrient reserves acquired during adult maturation (Toom et al., 1976). In contrast, $\mathbf{P}$ queens mate in the natal nest, where they attempt to become egg layers, or they participate in mating flights and seek adoption into other $\mathbf{P}$ nests (Glancey \& Lofgren, 1988; Porter, 1991), and they do not acquire extensive reserves (Porter et al., 1988; Keller \& Ross, 1993a). The actual process of colony multiplication in the $\mathbf{P}$ form, termed budding, involves the emigration of queens and workers from the parent nest to establish a nearby daughter nest (Vargo \& Porter, 1989). Queens thus appear to be much less vagile in the $\mathbf{P}$ form than the $\mathbf{M}$ form. Furthermore, the differences in phenotype between young queens of each form (e.g. in amount of nutrient reserves), coupled with a strong preference of $\mathbf{P}$ workers for the $\mathbf{P}$-queen phenotype, make it unlikely that queens often become egg layers in nests of the alternate form (Ross \& Shoemaker, 1993; Shoemaker \& Ross, 1996). This suggests that gene flow between the forms can be mediated by males only. Indeed, several studies indicate that interform gene flow commonly occurs by means of $\mathbf{P}$ queens mating with migrant M males (Ross \& Shoemaker, 1993; Ross, 1997).
The differences in social organization and its correlates between the two social forms of $S$. invicta lead to the following predictions concerning genetic structure in sympatric populations: (i) strong microgeographical structure in mtDNA variation exists in the $\mathbf{P}$ form but is absent in the $\mathbf{M}$ form; (ii) microgeographical structure in nuclear gene variation is absent in both forms; (iii) strong mtDNA differentiation exists between the forms; and (iv) nuclear gene differentiation is absent between the forms. We tested these predictions by surveying the hierarchical distribution of variation at nuclear and mtDNA markers in an area of sympatry in the introduced range. The patterns of genetic structure observed not only match the patterns predicted, they also yield potential insights into the manner by which polygyny spreads.

\section{Materials and methods}

\section{Sample collection}

Most samples of $S$. invicta were collected from northern Georgia, U.S.A. (Clarke, Morgan, Oconee, and Walton Counties; Fig. 1). Polygyny was first detected in this area in the late 1970s just east of the town of Monroe and was conspicuous at the time because all nearby populations were monogyne (Fletcher, 1983). Polygyny gradually expanded outward in all directions from its original locus, creating a large core $\mathbf{P}$ population in which monogyny is absent. It also spread more rapidly in a saltational manner towards the east, the direction of the prevailing winds during major mating flights, with the result that a mosaic distribution of the two forms has been created between Mt. Vernon and Eastville. The approximate chronological sequence of this eastward spread of the $\mathbf{P}$ form is indicated in Fig. 2.

Nests of the $\mathbf{P}$ form were sampled from six sites lying along a transect parallel to the prevailing winds and spanning an area from the western boundary of the core $\mathbf{P}$ population to the most easterly, recently established $\mathbf{P}$ sites outside of Athens (Fig. 1). Polygyny was confirmed in each $\mathbf{P}$ nest by finding two or more wingless queens. Nests of the $\mathbf{M}$ form were sampled from three sites, one each at the upwind and downwind ends of the $\mathbf{P}$ transect and one $30 \mathrm{~km}$ south of it (Fig. 1). Monogyny was confirmed in each $\mathbf{M}$ nest by examining the genotypes of at least eight nest-mates at five polymorphic allozyme loci to ensure the presence of genotype distributions expected in colonies headed by a single monandrous queen (Shoemaker et al., 1992). Wingless queens from $\mathbf{P}$ nests and winged queens from $\mathbf{M}$ nests were 


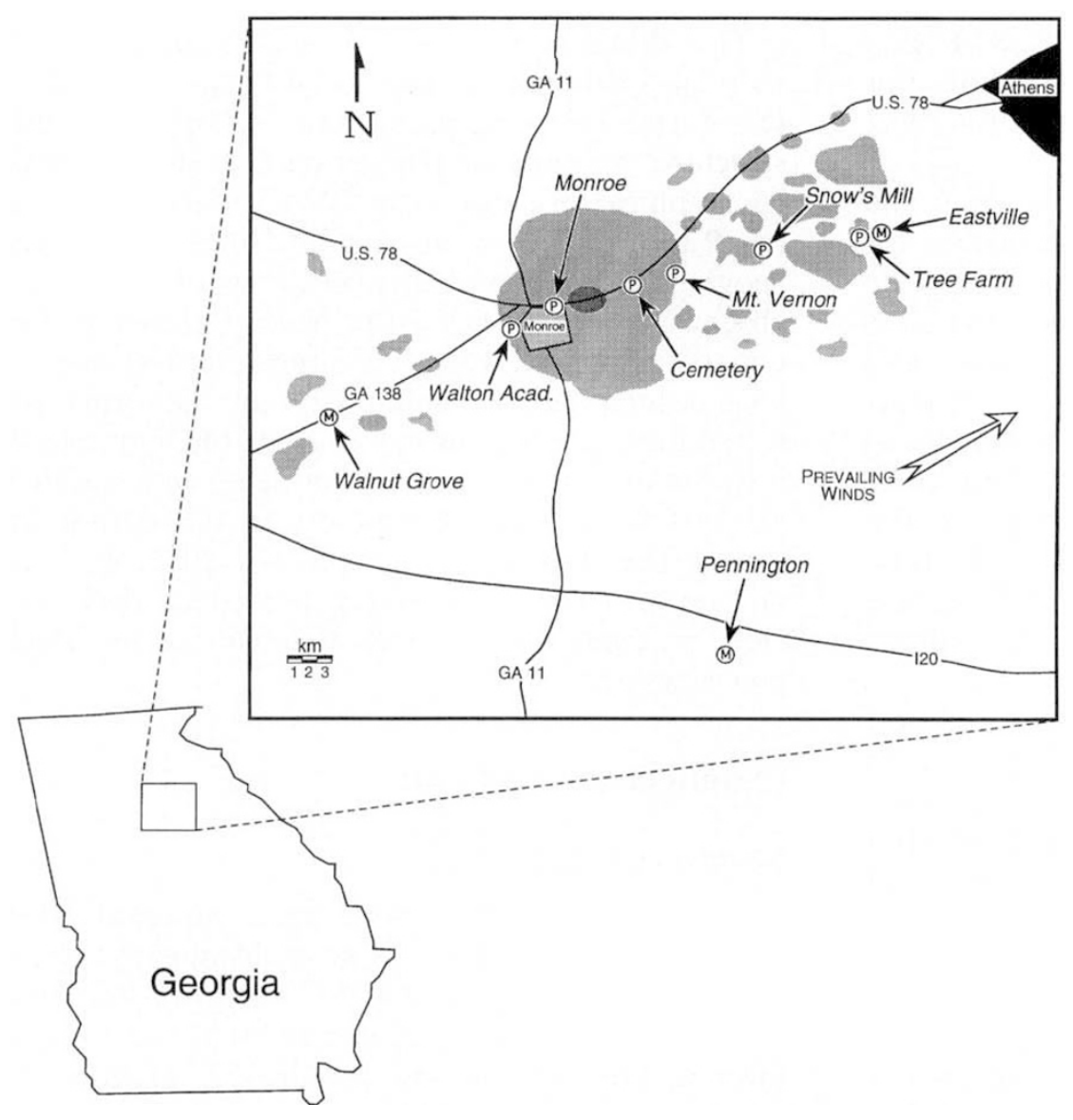

Fig. 1 Distributions of the monogyne (M) and polygyne (P) social forms of Solenopsis invicta in northern Georgia, U.S.A., and locations of nine sampling sites for this study. Areas in which only $P$ nests occur are indicated by stippling; other areas are known or presumed to contain mostly $\mathbf{M}$ nests. The location where polygyny was first detected in this area (Fletcher, 1983) is indicated by the darkest shading in the centre of the core $\mathbf{P}$ population. The current distributions were mapped by visiting several hundred sites during 1995 and 1996 and inferring the social organization of 6-10 nests per site using informative field criteria (Greenberg et al., 1985). The mean direction of the prevailing winds during major mating flights is shown. the sources of protein and DNA used to score allozyme genotypes and mtDNA haplotypes. The mtDNA haplotypes of only a single queen per nest were scored, whereas genotypes at the nuclear loci were scored from up to 10 queens per nest.

Additional samples of polygyne $S$. invicta were collected outside of Georgia for comparative purposes. A total of 453 wingless queens collected from 30 nests in Travis Co., TX, were used to generate allozyme data, and 33 wingless queens collected from as many nests in Holmes Co., MS, were used to generate mtDNA data.

\section{Assessment of allozyme variation}

Genotypes at seven polymorphic allozyme loci (Table 1) were determined by means of starch gel electrophoresis. Each locus is effectively biallelic in the U.S.A., and progeny studies have confirmed Mendelian inheritance of their products (Shoemaker et al., 1992). Data from Pgm-3 were not included in analyses of the $\mathbf{P}$ sites or comparisons between the social forms because this locus is affected by selection in polygyne $S$. invicta (Ross, 1992).

\section{Assessment of mtDNA variation}

A 4-kb portion of the mtDNA (including the $\mathrm{A}+\mathrm{T}$-rich noncoding region) was $\mathrm{PCR}$-amplified using the primer SR-J-14612 (5'-AGGGTATCTAATCCTAGTTT-3'; Simon et al., 1994) and a primer we designed (DDS-COII4; 5'-TAAGATGGTAATGAAGAGTAG-3'). One end of the 4-kb product was sequenced and aligned with honey bee sequence (Crozier \& Crozier, 1993) to confirm that the target region of the mtDNA molecule was amplified. Maternal inheritance of the fragment was demonstrated by examining the variable digestion products obtained from the restriction enzyme TaqI in nestmates from $10 \mathbf{M}$ colonies. PCR reactions were performed in $100 \mu \mathrm{L}$ volumes containing $10 \times$ buffer, $0.1 \mathrm{~mm}$ each of dATP, dCTP, dTTP and dGTP, $3.5 \mathrm{~mm}$ of $\mathrm{MgCl}_{2}, 25 \mathrm{pmol}$ of each primer, $100 \mathrm{ng}$ of template DNA, and $5 \mathrm{U}$ of Taq DNA polymerase. Amplifications were carried out in a thermal cycler programmed as follows: $1 \mathrm{~min}$ at $94^{\circ} \mathrm{C}$ for one cycle; $30 \mathrm{~s}$ at $94^{\circ} \mathrm{C}, 1 \mathrm{~min}$ at $50^{\circ} \mathrm{C}$, and $4.5 \mathrm{~min}$ at $68^{\circ} \mathrm{C}$ for 30 cycles; $5 \mathrm{~min}$ at $72^{\circ} \mathrm{C}$ for one terminal cycle. The amplified PCR products were 
Fig. 2 Chronological sequence of the eastward spread of the polygyne (P) form of Solenopsis invicta from its original locus of establishment in northern Georgia (area of darkest shading), and frequency of mtDNA haplotype $\mathrm{C}$ at six $\mathbf{P}$ sites spanning the study area. Bars indicate the 95 per cent confidence intervals about the haplotype frequencies. Haplotype $\mathrm{C}$ has not been found in the monogyne (M) form in Georgia.

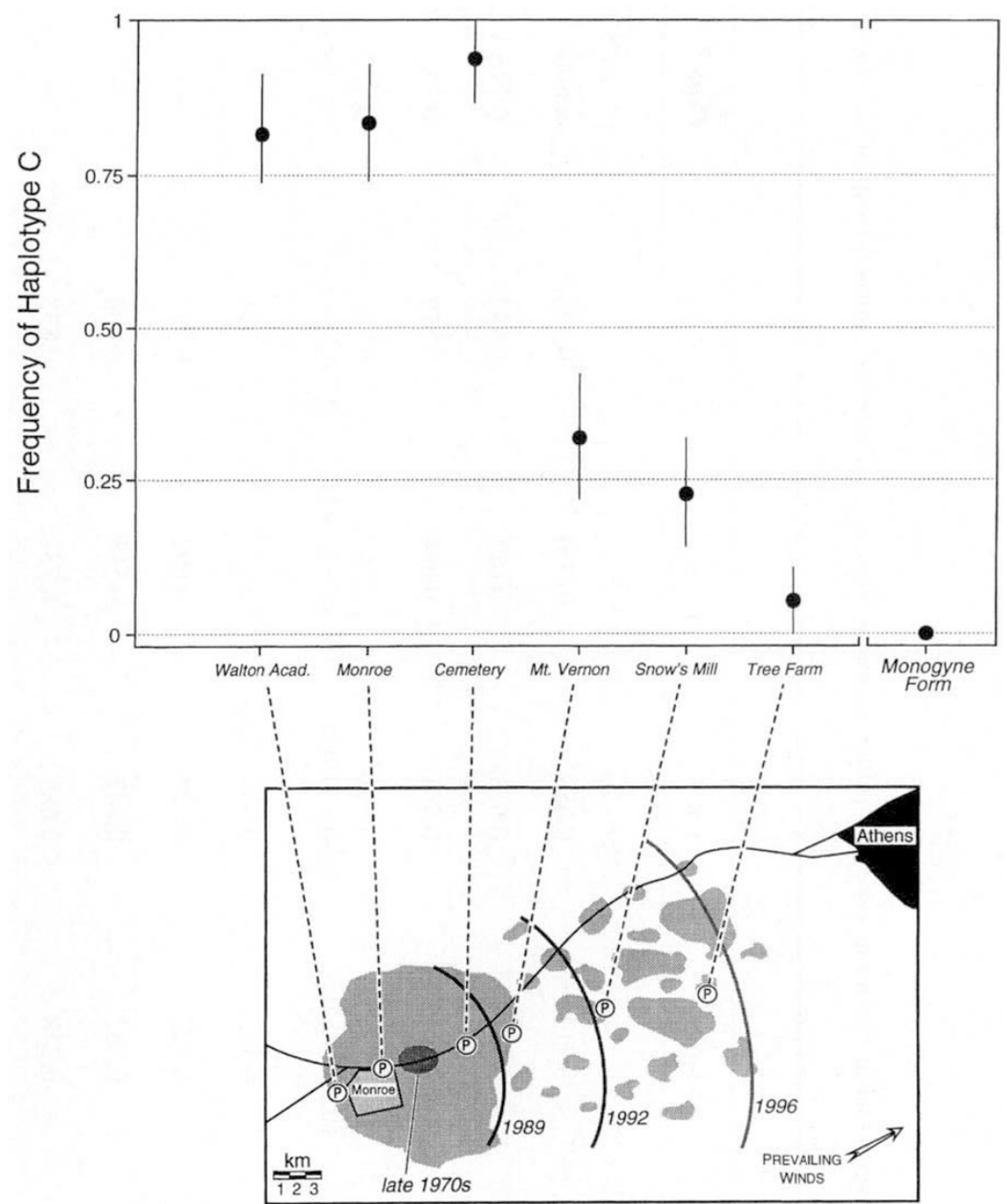

digested with the restriction enzymes BamHI, DpnII, EcoRV, Eco RI, HaeIII, HhaI, HindIII, HinfI, KpnI, $M s p \mathrm{I}, R s a \mathrm{I}, T a q \mathrm{I}$ and $X b a \mathrm{I}(5-8 \mu \mathrm{L}$ per reaction). Digestion products were electrophoresed in 1.5 per cent agarose gels, stained with ethidium bromide, and visualized under UV light. The presence or absence of restriction sites inferred using complete and partial digestion procedures defined the composite haplotypes.

\section{Genetic data analyses}

Nuclear (allozyme) markers Allele frequencies at sites from which a single ant per nest was collected were computed from genotype frequencies using all individuals. The 95 per cent confidence intervals (CIs) about the allele frequency estimates for the pooled Georgia $\mathbf{P}$ sites were obtained by drawing 1000 bootstrap samples from the original pooled data sets and dropping the 25 highest and 25 lowest allele frequency estimates. Genotype frequencies at each site were tested for correspondence to HardyWeinberg equilibrium (HWE) using $\chi^{2}$-tests with small-sample and continuity corrections (Lessios, 1992).

Estimates of allele frequencies and tests for correspondence to HWE are more complicated for the sites at which several ants per nest were genotyped because the potential nonindependence of nest-mate genotypes must be taken into account. A resampling procedure was employed in which a single genotype was drawn at random from each nest at a site, yielding a distribution of independent genotypes. Allele frequencies were estimated as the arithmetic mean frequencies for 1000 such resampled genotype distributions per site. The 95 per cent CIs about the allele frequency estimates were obtained by dropping the 50 extreme values derived from the 1000 


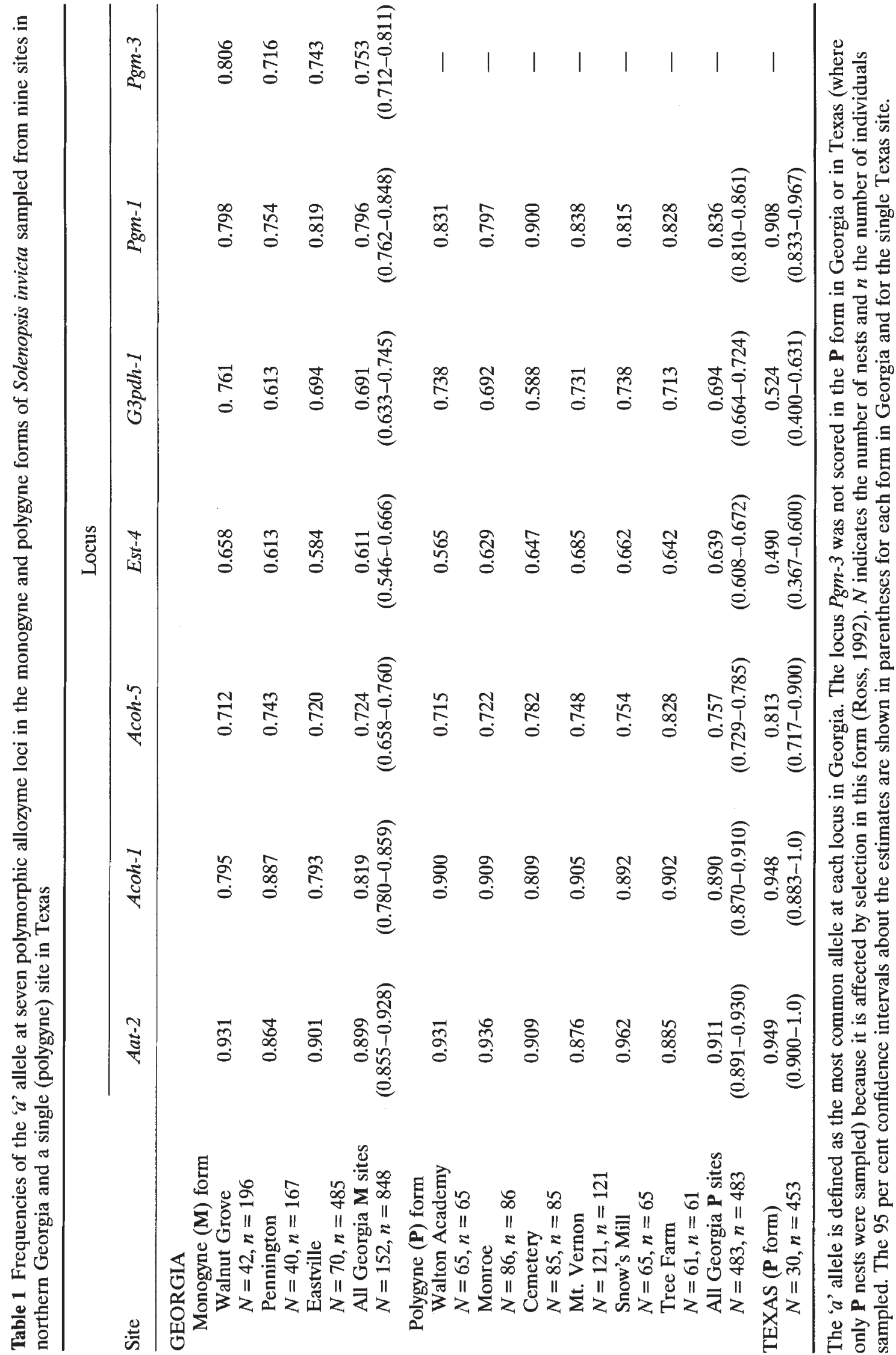

(C) The Genetical Society of Great Britain, Heredity, 78, 590-602. 
resampled genotype distributions. Genotype frequencies at each site were tested for correspondence to HWE by applying $\chi^{2}$-tests to each of the 1000 resampled genotype distributions and determining the proportions of tests that yielded values of $\chi^{2}$ greater than the critical value for $\alpha=0.05$.

Genetic differentiation among sites and between the forms in Georgia was assessed in several ways. (i) Fisher's exact probabilities of allelic differentiation among sites (combined over loci) were computed using the program GENEPOP (Raymond \& Rousset, 1995). (ii) Genetic distances (Nei's $D$ ) were estimated for all pairs of sites using the program of Sattler \& Hilburn (1985). Estimates of $D$ were based on the six polymorphic allozyme loci as well as 72 other protein-encoding loci previously shown to be effectively monomorphic in S. invicta in the U.S.A. (Ross et al., 1993). Mean pairwise distances and their variances were generated for particular classes of paired sites by jackknifing over the relevant pairs, and 95 per cent CIs about the means were estimated by assuming the $t$ distribution. Also, the $D$-values were employed in an explicit test for differentiation between the social forms in Georgia by calculating the $U$-statistic of Mueller \& Ayala (1982). (iii) Values of the fixation index $F_{\mathrm{ST}}$ were estimated at a single level (sites) and at two hierarchical levels (sites within forms) using the methods of Weir \& Cockerham (1984). Bias-corrected estimates of these $F$-statistics and their variances were obtained by jackknifing over loci (95 per cent CIs were generated by assuming the $t$ distribution). (iv) Values of the coefficient of gene differentiation, $G_{\mathrm{ST}}$, were estimated at the same levels using the methods of Nei (1987). Estimates of these $G$-statistics and their variances were obtained by jackknifing over loci.

Values of $F_{\mathrm{ST}}$ estimated for all pairs of Georgia sites were used to compute genetically effective migration rates $(\hat{M})$ using eqn $(6)$ of Slatkin (1993). Values of $\log _{10}(\hat{M})$ were regressed on values of $\log _{10}(d)$, where $d$ is the geographical distance between sites, to search for any signal of isolation by distance.

$m t D N A$ markers Haplotype frequencies at each site were computed using all sampled individuals (one per nest), with the 95 per cent CIs obtained by drawing 1000 bootstrap samples from the original data sets and dropping the 50 extreme values. Haplotype differentiation was studied using the analysis of molecular variance (AMOVA) approach of Excoffier et al. (1992), as implemented in the program winAmova. This method partitions haplotype diversity within and between different levels of hierarchical population subdivision, yielding analogues to $F$-statistics designated as $\Phi$-statistics. The probabilities that the values of $\Phi_{\mathrm{ST}}$ at various levels are significantly positive (indicating differentiation) were determined by permutation analysis using 1000 randomly permuted distance matrices.

\section{Relationships among sites based on mtDNA haplotype composition}

A tree (phenogram) describing the hierarchical genetic relationships of sites was constructed from the mtDNA data using the method of Holsinger \& Mason-Gamer (1996), as implemented in the program NUCLEODIV. The statistical significance of each node was assessed by permutation analysis using 10000 randomly permuted haplotype distributions.

\section{Results}

\section{Nuclear genetic structure}

Only one of 36 tests ( 2.8 per cent) for HWE at the Georgia $\mathbf{P}$ sites indicated a significant departure of the observed genotype frequencies from those expected. Genotype frequencies pooled over these sites accorded with frequencies expected under HWE at all six surveyed loci. Only one of 21 tests (4.8 per cent) indicated a significant departure from HWE at the Georgia $\mathbf{M}$ sites, and genotype frequencies pooled over these sites accorded with HWE at all seven surveyed loci. Thus, genotype frequencies within each social form of $S$. invicta in Georgia generally match Hardy-Weinberg expectations.

Allele frequencies at the allozyme loci are shown for each site and for the sites pooled within each form in Georgia in Table 1. The two forms share identical alleles at the six loci scored in both, and each of these alleles occurs at similar frequencies at the various sampling sites. The 95 per cent CIs for the frequencies of the most common alleles overlap broadly between the forms for all but one locus. These data suggest that little nuclear genetic differentiation exists among sites or between the forms in the Georgia study area. On the other hand, there is evidence for more extensive differentiation between the Georgia and Texas ants, as the 95 per cent CIs for allele frequencies in Georgia do not overlap with those for Texas in one-third of the comparisons.

Results of the formal hierarchical analyses confirm that nuclear gene differentiation among sites and between forms is minimal in Georgia (Table 2). The great preponderance of the total nuclear diversity (around 99 per cent) resides within 
Table 2 Hierarchical analysis of nuclear genetic diversity for variable allozyme loci in the monogyne and polygyne forms of Solenopsis invicta sampled from nine sites in northern Georgia

\begin{tabular}{lccc}
\hline & $\begin{array}{c}\text { Per cent of total } \\
\text { diversity }\end{array}$ & $G$-statistics & F-statistics \\
\hline All samples & & & \\
$\quad$ Between social forms & 0.5 & $G_{\mathrm{FT}}=0.005(-0.001-0.010)$ & $F_{\mathrm{FT}}=0.002(-0.003-0.007)$ \\
$\quad$ Among sites & 0.7 & $G_{\mathrm{SF}}=0.007(-0.007-0.020)$ & $F_{\mathrm{SF}}=0.005(-0.001-0012)$ \\
$\quad$ Within forms & $(1.2)$ & $G_{\mathrm{ST}}=0.012(-0.002-0.025)$ & $F_{\mathrm{ST}}=0.004(-0.001-0.009)$ \\
$\quad$ All sites & 98.8 & & \\
$\quad$ Within sites & 0.3 & $G_{\mathrm{SF}}=0.003(-0.013-0.018)$ & $F_{\mathrm{SF}}=0.003(-0.003-0.009)$ \\
Monogyne (M) form & 99.7 & & \\
$\quad$ Among sites & & & \\
$\quad$ Within sites & 0.8 & $G_{\mathrm{SF}}=0.008(-0.015-0.031)$ & $F_{\mathrm{SF}}=0.004(0.000-0.009)$ \\
Polygyne (P) form & 99.2 & & \\
$\quad$ Among sites & & & \\
\hline
\end{tabular}

The total genetic diversity is partitioned among three levels in the upper part of the table (based on estimates of the $G$-statistics): between forms, among sites, and within sites. The proportion of diversity among all sites (in parentheses) is the sum of the diversity between forms and the diversity among sites within forms. The statistics $G_{\mathrm{FT}}$ and $F_{\mathrm{FT}}$ measure the extent of differentiation between forms, $G_{\mathrm{SF}}$ and $F_{\mathrm{SF}}$ measure differentiation among sites within each form, and $G_{\mathrm{ST}}$ and $F_{\mathrm{ST}}$ measure differentiation among all sites. The 95 per cent confidence intervals about the estimates of differentiation are shown in parentheses.

sites, with somewhat more of the remaining small amount apportioned among sites than between the forms. Accordingly, values of all $G$-statistics and $F$-statistics for the site and form levels are small, with the 95 per cent CIs invariably overlapping zero. Considering the two forms separately, a slightly greater proportion of the diversity occurs among sites in the $\mathbf{P}$ form than in the $\mathbf{M}$ form, and the 95 per cent $\mathrm{CI}$ for the value of the $F$-statistic measuring among-site differentiation within the $\mathbf{P}$ form $\left(F_{\mathrm{SF}}\right)$ just overlaps zero (Table 2). Thus, there is a hint of slight nuclear differentiation among sites in the $\mathbf{P}$ form but not the $\mathbf{M}$ form.

Exact tests reveal that significant allele frequency differentiation exists among all Georgia sites $\left(\chi_{12}^{2}=25.8, P=0.012\right)$, but considering the forms separately, $\mathbf{P}$ sites exhibit significant differentiation $\left(\chi_{12}^{2}=23.1, P=0.027\right)$ whereas $\mathbf{M}$ sites do not $\left(\chi_{14}^{2}=12.5, P=0.569\right)$. These results support the suggestion from the estimates of $F_{\mathrm{SF}}$ that slight but significant microgeographical nuclear structure exists in the $\mathbf{P}$ form but not the $\mathbf{M}$ form.

Nuclear genetic structure was explored further by examining values of Nei's $D$ estimated for all pairs of sites. Within Georgia, the average genetic distance between $\mathbf{M}$ sites is lower than that between P sites, although the 95 per cent CIs for the mean distance within each form overlap. The CI for the $\mathbf{M}$ form overlaps zero, whereas that for the $\mathbf{P}$ form does not. These results again suggest that the $\mathbf{P}$ form but not the $\mathbf{M}$ form exhibits slight microgeographical nuclear structure. Average $D$ between sites of the alternate forms is intermediate to the average $D$ within each form and, as expected given this pattern, application of the Mueller/Ayala test shows that the between-form $D$-values do not differ significantly from the within-form values. This result supports the hierarchical analyses of structure showing no meaningful nuclear differentiation between the forms.

Values of $D$ between the Georgia and Texas sites significantly exceed the values between the Georgia sites, as indicated by the fact that the 95 per cent $C I$ for the mean $D$ between the states does not overlap with the CIs for mean $D$ within Georgia. This result demonstrates nuclear differentiation between ants from the two states that surpasses any microgeographical differentiation occurring within the Georgia study area.

No evidence for an effect of isolation by distance on nuclear differentiation exists for the sites within Georgia. Geographical distance $(d)$ is a poor predictor of genetic differentiation between sites, with $\log (d)$ explaining less than 1 per cent of the variation in $\log (\hat{M})$ in the regressions $(P=0.66$ for all sites, and $P=0.92$ for $\mathbf{P}$ sites only).

(C) The Genetical Society of Great Britain, Heredity, 78, 590-602. 


\section{Mitochondrial genetic structure}

Six restriction enzymes either failed to cut the $4-\mathrm{kb}$ PCR product (EcoRV, EcoRI, KpnI, RsaI and $X b a \mathrm{I}$ ) or cut the product identically among all individuals (HindIII). The remaining seven enzymes produced variable banding patterns among individuals that constituted a total of four composite mtDNA haplotypes (designated A, B, C and D).

Haplotype frequencies at the Georgia and Mississippi study sites are shown in Table 3. In Georgia, haplotype A predominates in the $\mathbf{M}$ form, where it is present at similar frequencies at all three sites. This haplotype is highly variable in frequency in the $\mathbf{P}$ form, ranging from being almost completely absent at the Cemetery site to being virtually fixed at the Tree Farm site. Haplotype $C$ is the most common haplotype overall in the $\mathbf{P}$ form in Georgia (though variable from site to site) and in Mississippi, but it is completely absent in the $\mathbf{M}$ form. Pooling all sites of each form in Georgia, the 95 per cent CIs for the frequencies of three of the four haplotypes do not overlap between the forms (Table 3 ).

Results of the hierarchical analyses of mtDNA structure are presented in Table 4 . In contrast to the nuclear markers, a large proportion of the mtDNA diversity exists at all three levels analysed: within sites, among sites, and between the forms. Considering all samples together, the greatest amount of haplotype diversity (about 40 per cent) resides within sites, with a somewhat lesser amount found among the sites within each form. Significantly, one-quarter or more of the total diversity is found between the social forms. Values for all of the

Table 3 Frequencies of four mtDNA haplotypes in the monogyne and polygyne forms of Solenopsis invicta sampled from nine sites in northern Georgia and a single (polygyne) site in Mississippi

\begin{tabular}{|c|c|c|c|c|}
\hline \multirow[b]{2}{*}{ Site } & \multicolumn{4}{|c|}{ Haplotypes } \\
\hline & A & B & $\mathrm{C}$ & $\mathrm{D}$ \\
\hline \multicolumn{5}{|l|}{ GEORGIA } \\
\hline \multicolumn{5}{|l|}{ Monogyne (M) form } \\
\hline $\begin{array}{l}\text { Walnut Grove } \\
N=43\end{array}$ & $\begin{array}{c}0.837 \\
(0.720-0.930)\end{array}$ & $\begin{array}{c}0.163 \\
(0.070-0.280)\end{array}$ & 0 & 0 \\
\hline $\begin{array}{l}\text { Pennington } \\
N=38\end{array}$ & $\begin{array}{c}0.894 \\
(0.868-1.0)\end{array}$ & $\begin{array}{c}0.053 \\
(0-0.132)\end{array}$ & 0 & $\begin{array}{c}0.053 \\
(0-0.132)\end{array}$ \\
\hline Eastville & 0.867 & 0.118 & 0 & 0.015 \\
\hline$N=68$ & $(0.779-0.941)$ & $(0.044-0.191)$ & & $(0-0.044)$ \\
\hline $\begin{array}{l}\text { All Georgia M sites } \\
n=149\end{array}$ & $\begin{array}{c}0.866 \\
(0.805-0.919)\end{array}$ & $\begin{array}{c}0.114 \\
(0.060-0.168)\end{array}$ & 0 & $\begin{array}{c}0.020 \\
(0-0.047)\end{array}$ \\
\hline \multicolumn{5}{|l|}{ Polygyne (P) form } \\
\hline $\begin{array}{l}\text { Walton Academy } \\
N=63\end{array}$ & 0.159 & $\begin{array}{c}0.032 \\
(0-0.079)\end{array}$ & $\begin{array}{c}0.809 \\
(0.961)\end{array}$ & 0 \\
\hline $\begin{array}{l}N=63 \\
\text { Monroe }\end{array}$ & $\begin{array}{c}(0.079-0.254) \\
0167\end{array}$ & $\begin{array}{l}(0-0.0 / 9) \\
0\end{array}$ & $\begin{array}{c}(0.746-0.921) \\
0.833\end{array}$ & \\
\hline $\begin{array}{l}\text { Monroe } \\
N=54\end{array}$ & $\begin{array}{c}0.167 \\
(0.074-0.259)\end{array}$ & 0 & $\begin{array}{c}0.833 \\
(0.741-0.926)\end{array}$ & 0 \\
\hline Cemetery & 0.057 & 0 & 0.943 & 0 \\
\hline$N=53$ & $(0-0.132)$ & & $(0.868-1.0)$ & \\
\hline $\begin{array}{l}\text { Mt. Vernon } \\
N=60\end{array}$ & $\begin{array}{l}0.700 \\
0.502\end{array}$ & 0 & 0.300 & 0 \\
\hline $\begin{array}{l}N=60 \\
\text { Snow's Mill }\end{array}$ & $\begin{array}{c}(0.505-0.000) \\
0.769\end{array}$ & 0 & 0.231 & 0 \\
\hline$N=65$ & $(0.677-0.862)$ & & $(0.138-0.323)$ & \\
\hline Tree Farm & 0.935 & 0.016 & 0.049 & 0 \\
\hline$N=61$ & $(0.869-0.984)$ & $(0-0.049)$ & $(0-0.115)$ & \\
\hline All Georgia $\mathbf{P}$ sites & 0.480 & 0.008 & 0.512 & 0 \\
\hline$N=356$ & $(0.430-0.531)$ & $(0-0.020)$ & $(0.455-0.559)$ & \\
\hline $\begin{array}{l}\text { MISSISSIPPI (P form) } \\
\quad N=33\end{array}$ & $\begin{array}{c}0.455 \\
(0.303-0.636)\end{array}$ & 0 & $\begin{array}{c}0.545 \\
(0.364-0.697)\end{array}$ & 0 \\
\hline
\end{tabular}

$N$ is the number of nests ( = individuals) sampled. The 95 per cent confidence intervals about the estimates are shown in parentheses. 
$\Phi$-statistics are significantly greater than zero, indicating significant mtDNA differentiation both among sites and between the forms in Georgia.

Considering the forms separately, virtually none of the mtDNA diversity in the $\mathbf{M}$ form occurs among sites and values of $\Phi_{\mathrm{SF}}$ are indistinguishable from zero. In contrast, over half of the diversity in the $\mathbf{P}$ form occurs among sites and values of $\Phi_{\mathrm{SF}}$ are significantly greater than zero (Table 4). The strong mtDNA differentiation between the forms and among $\mathbf{P}$ sites contrasts markedly with the relative lack of structure revealed by the nuclear markers.

One striking feature of the mtDNA data is the existence of a cline in the frequency of haplotype $\mathrm{C}$ from the centre of the core $\mathbf{P}$ population to the more easterly (downwind) $\mathbf{P}$ sites (Fig. 2). This haplotype is present at high frequencies near the location where the $\mathbf{P}$ form first appeared and declines steadily in frequency at $\mathbf{P}$ sites increasingly distant in the downwind direction from this original location. At the $\mathbf{P}$ site farthest downwind from the core population (Tree Farm), fewer than 5 per cent of the ants possess this haplotype, a frequency statistically indistinguishable from zero, the frequency in the $\mathbf{M}$ form. Survey records indicate that polygyny has spread eastward from the original site of establishment according to the time sequence depicted in Fig. 2. Thus, the frequency of haplotype $\mathrm{C}$ is related to the recency of appearance of polygyny at our study sites, with sites that developed polygyny most recently least resembling the original polygyne founder population.

\section{Relationships among sites based on mtDNA haplotype composition}

The tree describing hierarchical relationships among the Georgia sites based on mtDNA haplotype composition is shown in Fig. 3. The two major groups evident in this tree are distinguished by whether or not the included sites have a high frequency of haplotype $\mathrm{C}$. One of the groups includes sites located around the original locus of polygyny near Monroe; all of these sites have haplotype $\mathrm{C}$ present at a frequency greater than 0.8 . The other group includes all of the $\mathbf{M}$ sites, as well as the three $\mathbf{P}$ sites where polygyny appeared subsequent to its initial establishment; all of these sites have haplotype $\mathrm{C}$ present at a frequency of 0.3 or less. Within the latter group, the $\mathbf{P}$ site in which polygyny

Table 4 Hierarchical analysis of mtDNA haplotype diversity in the monogyne and polygyne forms of Solenopsis invicta sampled from nine sites in northern Georgia

\begin{tabular}{|c|c|c|c|c|c|c|}
\hline & \multicolumn{3}{|c|}{ Equidistant metric } & \multicolumn{3}{|c|}{ Euclidean metric } \\
\hline & $\begin{array}{l}\text { Per cent of total } \\
\text { diversity }\end{array}$ & $\Phi$-statistics & $P$ & $\begin{array}{l}\text { Per cent of total } \\
\text { diversity }\end{array}$ & $\Phi$-statistics & $P$ \\
\hline All samples & & & & & & \\
\hline $\begin{array}{l}\text { Between social forms } \\
\text { Among sites }\end{array}$ & 24.5 & $\Phi_{\mathrm{FT}}=0.245$ & 0.045 & 28.7 & $\Phi_{\mathrm{FT}}=0.287$ & 0.022 \\
\hline $\begin{array}{l}\text { Within forms } \\
\text { All sites } \\
\text { Within sites }\end{array}$ & $\begin{array}{c}33.5 \\
(58.0) \\
42.0\end{array}$ & $\begin{array}{l}\Phi_{\mathrm{SF}}=0.443 \\
\Phi_{\mathrm{ST}}=0.579\end{array}$ & $\begin{array}{l}<0.001 \\
<0.001\end{array}$ & $\begin{array}{c}33.2 \\
(61.9) \\
38.1\end{array}$ & $\begin{array}{l}\Phi_{\mathrm{SF}}=0.465 \\
\Phi_{\mathrm{ST}}=0.619\end{array}$ & $\begin{array}{l}<0.001 \\
<0.001\end{array}$ \\
\hline $\begin{array}{l}\text { Monogyne (M) form } \\
\text { Among sites } \\
\text { Within sites }\end{array}$ & $\begin{array}{r}0 \\
100\end{array}$ & $\Phi_{\mathrm{SF}}=0$ & 0.444 & $\begin{array}{r}0.5 \\
99.5\end{array}$ & $\Phi_{\mathrm{SF}}=0.005$ & 0.294 \\
\hline $\begin{array}{l}\text { Polygyne }(\mathbf{P}) \text { form } \\
\text { Among sites } \\
\text { Within sites }\end{array}$ & $\begin{array}{l}50.3 \\
49.7\end{array}$ & $\Phi_{\mathrm{SF}}=0.503$ & $<0.001$ & $\begin{array}{l}50.2 \\
49.8\end{array}$ & $\Phi_{\mathrm{SF}}=0.502$ & $<0.001$ \\
\hline
\end{tabular}

The equidistant metric assumes that all four observed haplotypes are equally divergent from one another, whereas the Euclidean metric is a distance measure that equals the square of the number of restriction site differences between haplotypes. The total haplotype diversity is partitioned among three levels in the upper part of the table: between forms, among sites, and within sites. The proportion of diversity among all sites (in parentheses) is the sum of the diversity between forms and the diversity among sites within forms. The statistic $\Phi_{\mathrm{FT}}$ measures the extent of differentiation between forms, $\Phi_{\mathrm{SF}}$ measures differentiation among sites within each form, and $\Phi_{\mathrm{ST}}$ measures differentiation among all sites. The probabilities that the estimates of the $\Phi$-statistics do not differ from zero (no differentiation) are shown under the heading 'P'. 


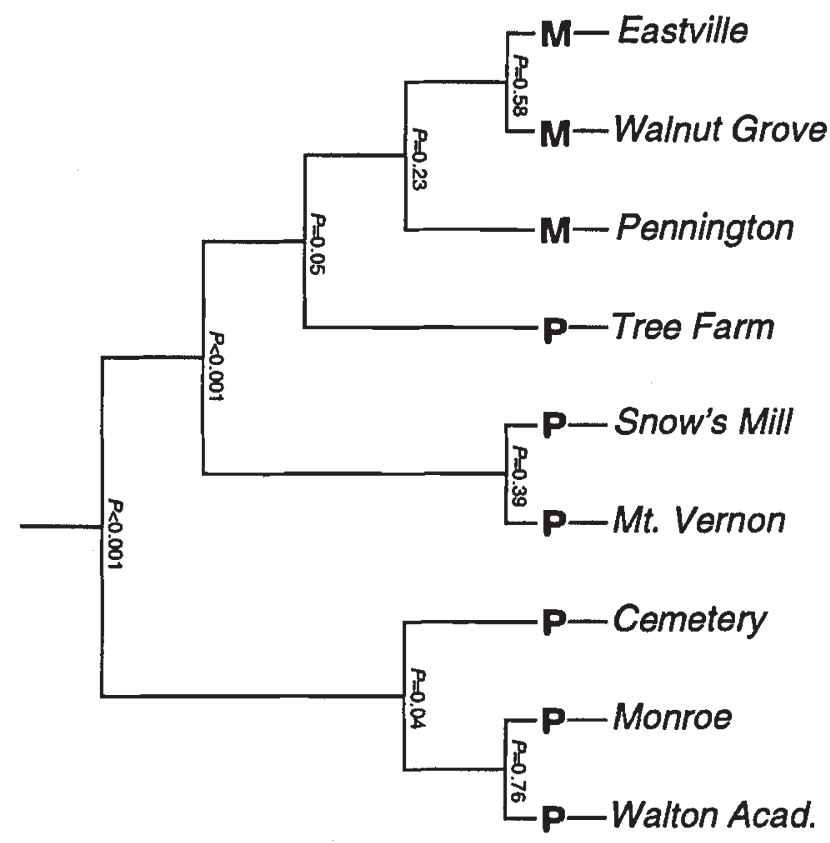

Fig. 3 Tree describing the hierarchical genetic relationships of Solenopsis invicta sites in northern Georgia based on mtDNA haplotype composition. The probability of the genetic differentiation at each node occurring by chance is shown. The social form at each site $(\mathbf{M}=$ monogyne, $\mathbf{P}=$ polygyne) is indicated next to the site name.

appeared most recently (Tree Farm) is more closely allied to the $\mathbf{M}$ sites than to other $\mathbf{P}$ sites. Furthermore, the Snow's Mill and Mt. Vernon $\mathbf{P}$ sites, which acquired polygyny before Tree Farm but were not part of the original $\mathbf{P}$ founder population, also show greater affinity to the $\mathbf{M}$ form than to the sites in the core $\mathbf{P}$ population. In general, the mtDNA tree features groupings of sites that are affiliated on the basis of geographical proximity and/or a common social organization.

\section{Discussion}

Queens of the two social forms of $S$. invicta apparently differ strongly in their vagility. As is frequently the case in polygyne ants (Bourke \& Franks, 1995; Ross \& Keller, 1995), queens of the $\mathbf{P}$ form seem often not to disperse very far from their natal nests. Young queens may mate and be recruited as new egg layers in their natal nest, a strategy that occurs at least occasionally in introduced populations (Porter, 1991) and is common in native populations (Ross et al., 1996). Even if they do not routinely mate within their nest in Georgia, $\mathbf{P}$ queens may nonetheless have restricted mating flights and be adopted into $\mathbf{P}$ nests close to the nest in which they eclosed (see Bourke \& Franks (1995) for examples from other polygyne ants). Limited female dispersal in the $\mathbf{P}$ form is suggested further by the presence of budding as an important mode of colony multiplication (Vargo \& Porter, 1989). In contrast, queens of the $\mathbf{M}$ form disperse widely during their mating flights (up to $10 \mathrm{~km}$ - Markin et al., 1971) and these queens only take up egg laying following such a flight, typically in conjunction with independent initiation of a new colony. Colony budding is not known in the $\mathbf{M}$ form. Assuming minimal femalemediated gene flow between the forms, a clear prediction emerging from the distinctive queen habits is that strong among-site differentiation in mtDNA variation should occur in the $\mathbf{P}$ form but not the $\mathbf{M}$ form, as we found.

Males of both forms presumably disperse widely prior to mating, and most $\mathbf{P}$ queens appear to mate with males originating from $\mathbf{M}$ nests rather than $\mathbf{P}$ nests (Ross \& Shoemaker, 1993). Extensive malemediated gene flow both within and between the forms is expected to reinforce nuclear genetic homogeneity across $\mathbf{M}$ sites resulting from high queen vagility, and largely to erase any signature of microgeographical structure in the $\mathbf{P}$ form caused by limited queen vagility. The results of our hierarchical analyses of nuclear genetic structure indeed show a lack of significant differentiation among sites, although some slight allelic differentiation among sites was detected in the $\mathbf{P}$ form using exact tests. Thus, low vagility of $\mathbf{P}$ queens, perhaps coupled with limitations on the dispersal of $\mathbf{P}$ males (Sundström, 1995), appears to have left a weak imprint in the patterning of nuclear variation in the polygyne form. Nonetheless, nuclear gene flow is sufficiently extensive at all levels to prevent detection of any signal of isolation by distance among sites.

Significant local genetic structure has been detected in a diversity of polygyne ants using nuclear or mtDNA markers (Ross \& Keller, 1995), although the two sets of markers have not previously been employed in concert to study microgeographical structure in social insects. Studies using nuclear markers have documented the occurrence of local structure in polygyne populations and its absence in monogyne populations of the same or closely related species in the ant genera Formica (Pamilo \& Rosengren, 1984; Sundström, 1993) and Myrmica (Seppä \& Pamilo, 1995; Banschbach \& Herbers, 1996), as well as in native $S$. invicta (unpublished data). Such studies constitute the most compelling evidence that differences in social organization and its correlates lead to important differences in gene flow regimes and consequent variation in genetic 
structure. Even greater structure is to be expected for mtDNA markers in such polygyne ants, given that dispersal often may be accomplished primarily by males rather than queens (Sundström, 1995).

Physiological and behavioural differences in young queens of the two forms of $S$. invicta, coupled with preferences of $\mathbf{P}$ workers during the process of queen adoption, make it unlikely that queens often become egg layers in nests of the alternate type (thereby effecting interform gene flow). Young $\mathbf{M}$ queens acquire extensive nutrient reserves essential for long-distance mating flights and independent colony foundation (Toom et al., 1976). Young $\mathbf{P}$ queens generally acquire far fewer reserves and forego attempts at independent nest foundation, instead seeking adoption into their own or another P nest (Keller \& Ross, 1993a; Ross \& Keller, 1995). Lack of reserves is advantageous to young $\mathbf{P}$ queens seeking adoption because $\mathbf{P}$ workers have evolved a strong preference for queens with such phenotypes (Keller \& Ross, 1993b), but it is strongly disadvantageous to queens attempting to start a singlequeen nest independently (Porter et al., 1988). Thus, young $\mathbf{P}$ queens are physiologically ill-suited to initiate $\mathbf{M}$ nests, and young $\mathbf{M}$ queens possess inappropriate phenotypes for adoption into $\mathbf{P}$ nests. The specialized queen phenotypes produced by each form thus seem to generate significant obstacles to queen-mediated gene flow between them, leading to the strong interform mtDNA differentiation we report.

Few obstacles to interform gene flow occurring via males mating with queens of the alternate form are apparent from the natural history of these ants, and indeed, studies employing nuclear markers under differential selection in the two forms have demonstrated that $\mathbf{P}$ queens commonly mate with $\mathbf{M}$ males (although the converse type of mating, $\mathbf{M}$ queens with $\mathbf{P}$ males, seems to be rare; Shoemaker \& Ross, 1996). Extensive interform gene flow mediated by dispersing males is expected to homogenize the two forms at neutral nuclear genes, and as predicted, no evidence of differentiation between the forms was discerned at six allozyme loci. That these six loci are sufficiently sensitive markers for detecting structure caused by restricted gene flow is indicated by the significant differentiation found between the Georgia and Texas ants.

Fire ant populations in northern Georgia thus are structured in fundamentally different ways at their mitochondrial and nuclear genomes. Restricted queen dispersal in the $\mathbf{P}$ form and the inability of queens of either form to become reproductives in nests of the alternate type generate extensive
mtDNA differentiation both among $\mathbf{P}$ sites and between the forms. Extensive male dispersal coupled with the success of $\mathbf{M}$ males in inseminating $\mathbf{P}$ queens lead to a lack of substantial nuclear gene differentiation at either level.

\section{Scenario for the initiation and spread of polygyny}

The clinal distribution of mtDNA variation in the $\mathbf{P}$ form in our study area, combined with recent data on the genetic basis of polygyny in $S$. invicta, suggest a mechanism by which polygyny arises and spreads in introduced fire ants. A single Mendelian factor, designated here as $p f^{+}$(for polygyny factor), appears to be required for the expression of polygyny in $S$. invicta. This has been shown by virtue of the fact that all egg-laying $\mathbf{P}$ queens possess the single heterozygous genotype $B b$ at the marker gene $G p-9$, whereas all $\mathbf{M}$ queens possess the homozygous genotype $B B$ at this locus (Ross, 1997). Thus, allele $G p-9^{b}$ is in complete gametic disequilibrium with $p f^{+}$and $G p-9^{B}$ is in disequilibrium with the allelic factor $p f^{-}$. Polygyny has spread rapidly eastward from its site of origin near Monroe, and the points where it has arisen more recently show a decreasing resemblance to the founder population in their frequency of haplotype $\mathrm{C}$ (Fig. 2), with the frequency at the site where polygyny appeared most recently (Tree Farm) statistically indistinguishable from the frequency in the $\mathbf{M}$ form (zero). This suggests that polygyny has spread by means of monogyne queen lineages converting to polygyny, most likely as a result of acquiring $p f^{+}$.

Monogyne queen lineages presumably acquire $p f^{+}$ when $\mathbf{M}$ queens mate with $\mathbf{P}$ males that bear this factor (step 1 in Fig. 4). Such matings appear to be rare (Shoemaker \& Ross, 1996), but should be most common downwind (east) of the core $\mathbf{P}$ population and at zones of contact between large 'pure' stands of each social form. $\mathbf{M}$ queens mated to $\mathbf{P}$ males bearing $p f^{+}$establish monogyne nests in which all female progeny have the genotype $p f^{+} / p f^{-}$. Thus, the new female sexuals produced by such a colony can form multiple-queen colonies that will accept other $p f^{+} / p f^{-}$queens (step 2). Indeed, the fact that such heterozygous queens lack the extensive reserves required for independent founding ( $\mathrm{L}$. Keller \& $\mathrm{K}$. G. Ross, unpublished) and that they have never been found heading mature $\mathbf{M}$ colonies (Shoemaker \& Ross, 1996) suggests that they must associate to found polygyne nests or join previously established polygyne nests.

Once polygyny originates in a monogyne maternal lineage, the new polygyne nests will continually 
Fig. 4 Scenario for the spread of the polygyne social organization of Solenopsis invicta in the study area.

Monogyne queens never possess mtDNA haplotype $C$ nor the nuclear factor inducing polygyny, $p f^{+}$. These queens occasionally mate with polygyne males that possess $p f^{+}$(step 1), and the female sexual offspring from such matings, which possess genotype $p f^{+} / p f^{-}$on a monogyne mtDNA background (non-C haplotype), start polygyne colonies or join previously established polygyne colonies (step 2). Such new polygyne populations, which contain mostly monogyne mtDNA, increasingly adopt immigrant polygyne queens from upwind polygyne sites with higher frequencies of haplotype C. Thus, new polygyne populations eventually shift from high frequencies of non-C haplotypes to high frequencies of haplotype $\mathrm{C}$.
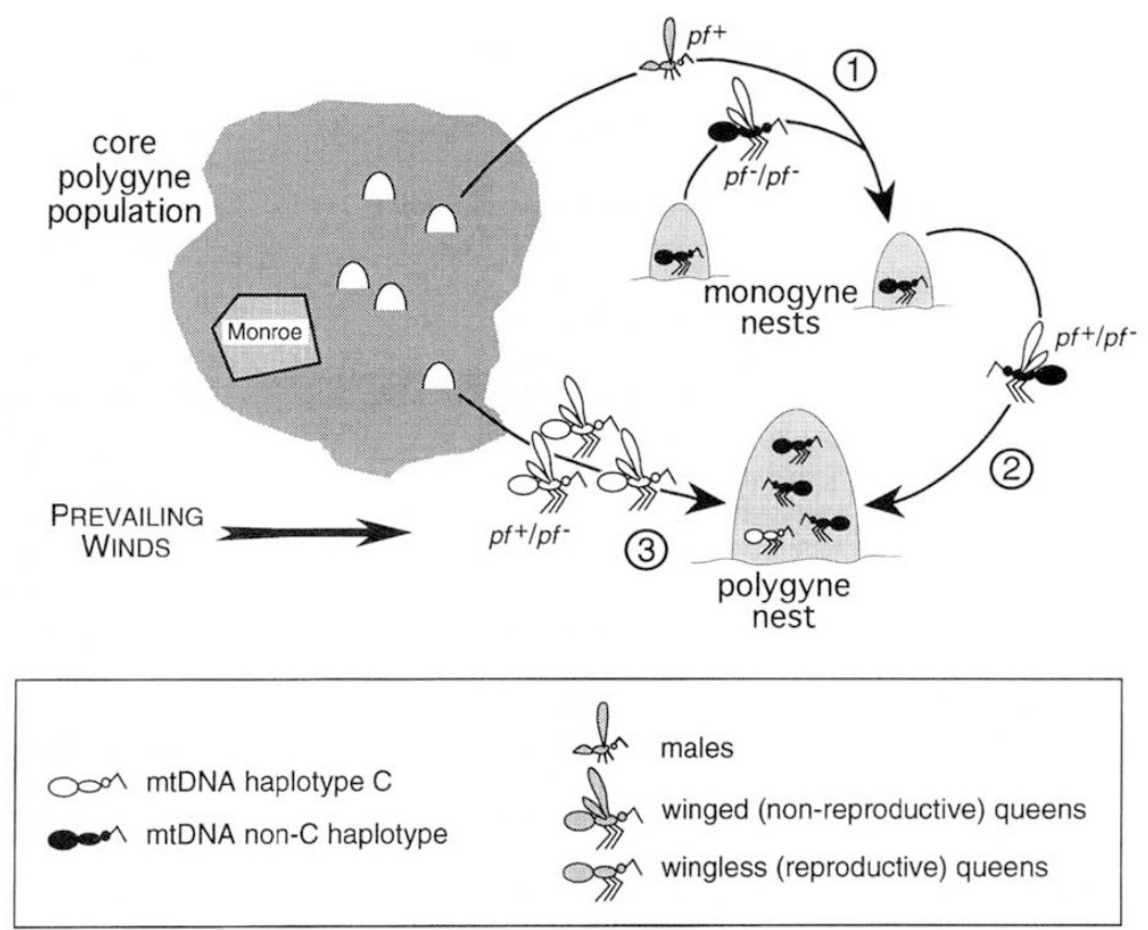

accept queens with genotype $p f^{+} / p f^{-}$. Early on, these will be mostly queens with monogyne mtDNA derived from the original conversion of monogyne maternal lineages with $p f^{+}$, but as the incipient polygyne population develops and $\mathbf{P}$ sites with high frequencies of polygyne mtDNA encroach from the west, an increasing frequency of adopted queens will be $\mathbf{P}$ queens with polygyne mtDNA immigrating from an upwind source (step 3). Thus, newly arisen polygyne populations are expected to contain mostly monogyne mtDNA when young, but to acquire polygyne mtDNA at increasing rates as they age. This explains the association between date of appearance of polygyny and frequency of haplotype $\mathrm{C}$ in the sites downwind of the core $\mathbf{P}$ population. This scenario implies that new $\mathbf{P}$ sites are more closely related to the local $\mathbf{M}$ form than to nearby $\mathbf{P}$ sites at their mtDNA when they first arise, but that they become increasingly similar to the source population for immigrant $\mathbf{P}$ queens over time. The tree of relationships among our study sites based on mtDNA haplotype composition (Fig. 3) accords with this expectation.

\section{Acknowledgements}

We thank C. DeHeer, J. Evans, M. Goodisman and L. Keller for comments on the manuscript and E. Vargo for providing samples. This research was partly funded by the National Geographic Society and the Georgia Agricultural Experiment Stations.
D.D.S. was supported by a grant from the U.S. Department of Agriculture to J. Jaenike.

\section{References}

AVISE, J. C. 1994. Molecular Markers, Natural History and Evolution. Chapman \& Hall, New York.

BANSCHBACH, v. S. AND HERBERS, J. M. 1996. Complex colony structure in social insects: I. Ecological determinants and genetic consequences. Evolution, 50, 285-297.

BARTON, N. AND Clark, A. 1990. Population structure and process in evolution. In: Wöhrmann, K. and Jain, S. K. (eds) Population Biology; Ecological and Evolutionary Viewpoints, pp. 115-173. Springer, Berlin.

BOURKE, A. F. G. AND FRANKS, N. R. 1995. Social Evolution in Ants. Princeton University Press, Princeton, NJ.

CHEPKO-SADE, B. D. AND HALPIN, Z. T. (eds) 1987. Mammalian Dispersal Patterns: The Effects of Social Structure on Population Genetics. University of Chicago Press, Chicago, IL.

CROZIER, R. H. AND CROZIER, Y. C. 1993. The mitochondrial genome of the honeybee Apis mellifera: complete sequence and genome organization. Genetics, 133, 97-117.

DONG, J. S. AND WAGNeR, D. B. 1994. Paternally inherited chloroplast polymorphism in Pinus: estimation of diversity and population subdivision, and tests of disequilibrium with a maternally inherited mitochondrial polymorphism. Genetics, 136, 1187-1194.

EXCOFFIER, L., SMOUSE, P. E. AND QUATTRO, J. M. 1992. Analysis of molecular variance inferred from metric distances among DNA haplotypes: application to 
human mitochondrial DNA restriction data. Genetics, 131, 479-491.

FLETCHER, D. J. C. 1983. Three newly discovered polygynous populations of the fire ant, Solenopsis invicta, and their significance. J. Georgia Entomol. Soc., 18, 538-543.

GLANCEY, B. M. AND LOFGREN, C. s. 1988. Adoption of newly mated queens: a mechanism for proliferation and perpetuation of polygynous red imported fire ants, Solenopsis invicta Buren. Florida Entomol, 71, 581-587.

GREENBERG, L., FLETCHER, D. J. C. AND VINSON, S. B. 1985. Differences in worker size and mound distribution in monogynous and polygynous colonies of the fire ant Solenopsis invicta Buren. J. Kansas Entomol. Soc., 58, 9-18.

HOELZER, G. A., DITTUS, W. P. J., ASHLEY, M. V. AND MELNICK, D. J. 1994. The local distribution of highly divergent mitochondrial DNA haplotypes in toque macaques Macaca sinica at Polonnaruwa, Sri Lanka. Mol. Ecol, 3, 451-458.

HOLSINGER, K. E. AND MASON-GAMER, R. J. 1996. Hierarchical analysis of nucleotide diversity in geographically structured populations. Genetics, 142, 629-639.

KELLER, L. AND ROSs, K. G. 1993a. Phenotypic plasticity and 'cultural' transmission of alternative social organizations in the fire ant Solenopsis invicta. Behav. Ecol. Sociobiol, , 33, 121-129.

KELleR, L. AND ROss, K. G. 1993b. Phenotypic basis of reproductive success in a social insect: genetic and social determinants. Science, 260, 1107-1110.

LEssios, H. A. 1992. Testing electrophoretic data for agreement with Hardy-Weinberg expectations. Mar. Biol., 112, 517-523.

MARKIN, G. P., DILLIER, J. H., HILl, s. O., BLUM, M. S. AND HERMANN, H. R. 1971. Nuptial flight and flight ranges of the imported fire ant, Solenopsis saevissima richteri (Hymenoptera: Formicidae). J. Georgia Entomol. Soc., 6, 145-156.

MUELLER, L. D. AND AYALA, F. J. 1982. Estimation and interpretation of genetic distance in empirical studies. Genet. Res., 40, 127-137.

NEI, M. 1987. Molecular Evolutionary Genetics. Columbia University Press, New York.

PAMILO, P. AND ROSENGREN, R. 1984. Evolution of nesting strategies of ants: genetic evidence from different population types of Formica ants. Biol. J. Linn. Soc., 21, 331-348.

PORTER, S. D. 1991. Origins of new queens in polygyne red imported fire ant colonies (Hymenoptera: Formicidae). J. Entomol. Sci., 26, 474-478.

PORTER, S. D., VAN EIMEREN, B. AND GILBERT, L. E. 1988. Invasion of red imported fire ants (Hymenoptera: Formicidae): microgeography of competitive replacement. Ann. Entomol. Soc. Am., 81, 913-918.

RAYMOND, M. AND ROUSSET, F. 1995. An exact test for population differentiation. Evolution, 49, 1280-1283.

Ross, K. G. 1992. Strong selection on a gene that influences reproductive competition in a social insect. Nature, 355, 347-349.
Ross, K. G. 1997. Multilocus evolution in fire ants: effects of selection, gene flow, and recombination. Genetics (in press).

ROSS, K. G. AND KELLER, L. 1995. Ecology and evolution of social organization: insights from fire ants and other highly eusocial insects. Ann. Rev. Ecol. Syst., 26, 631-656.

ROSS, K. G. AND SHOEMAKER, D. D. 1993. An unusual pattern of gene flow between the two social forms of the fire ant Solenopsis invicta. Evolution, 47, 1595-1605.

Ross, K. G., VARGO, E. L., Keller, L. AND TRAGER, J. C. 1993. Effect of a founder event on variation in the genetic sex-determining system of the fire ant Solenopsis invicta. Genetics, 135, 843-854.

ROSs, K. G., VARGO, E. L. AND KELLER, L. 1996. Social evolution in a new environment: the case of introduced fire ants. Proc. Natl. Acad. Sci. U.S.A., 93, 3021-3025.

SATTLER, P. W. AND HILBURN, L. R. 1985. A program for calculating genetic distance, and its use in determining significant differences in genetic similarity between two groups of populations. J. Hered., 76, 400.

SEPPÄ, P. AND PAMILO, P. 1995. Gene flow and population viscosity in Myrmica ants. Heredity, 74, 200-209.

SHOEMAKER, D. D. AND ROSS, K. G. 1996. Effects of social organization on gene flow in the fire ant Solenopsis invicta. Nature, 383, 613-616.

SHOEMAKER, D. D., COSTA, J. T. AND ROSS, K. G. 1992. Estimates of heterozygosity in two social insects using a large number of electrophoretic markers. Heredity, 69, 573-582.

SIMON, C., FRATI, F., BECKENBACH, A., CRESPI, B., LIU, H. AND FLOOK, P. 1994. Evolution, weighting, and phylogenetic utility of mitochondrial gene sequences and a compilation of conserved polymerase chain reaction primers. Ann. Entomol. Soc. Am., 87, 651-701.

SLATKIN, M. 1993. Isolation by distance in equilibrium and non-equilibrium populations. Evolution, 47, 264-279.

SUNDSTRÖM, L. 1993. Genetic population structure and sociogenetic organisation in Formica truncorum (Hymenoptera; Formicidae). Behav. Ecol. Sociobiol., 33, 345-354.

SUNDSTRÖM, L. 1995. Dispersal polymorphism and physiological condition of males and females in the ant, Formica truncorum. Behav. Ecol., 6, 132-139.

TOOM, P. M., CUPP, E., JOHNSON, C. P. AND GRIFFIN, I. 1976. Utilization of body reserves for minim brood development by queens of the imported fire ant, Solenopsis invicta. J. Insect Physiol., 22, 217-220.

VAN STAADEN, M. J., MICHENER, G. R. AND CHESSER, R. K. 1996. Spatial analysis of microgeographic genetic structure in Richardson's ground squirrels. Can. J. Zool., 74, 1187-1195.

VARGO, E. L. AND PORTER, S. D. 1989. Colony reproduction by budding in the polygyne form of the fire ant, Solenopsis invicta (Hymenoptera: Formicidae). Ann. Entomol. Soc. Am., 82, 307-313.

WEIR, B. S. AND COCKERHAM, C. C. 1984 . Estimating $F$-statistics for the analysis of population structure. Evolution, 38, 1358-1370. 